\title{
TCC's
}

\section{QUANTIFICAÇÃO DE RESÍDUOS SÓLIDOS DO REFILAMENTO DE MÁQUINA OVERLOQUE EM EMPRESAS FACCIONISTAS DE IBIRAMA/SC}

\author{
LUÍSA LIMA DE SOUZA |IFC \\ DAYANE GONZAGA DOMINGOS, M.SC.| IFC \\ ANA SILVIA DE LIMA VIELMO, M.SC. IFC
}

\section{INTRODUÇÃO}

A indústria têxtil é um setor de grande importância econômica e social, possuindo várias etapas produtivas. Estas etapas são fontes geradoras de resíduos sólidos, com destaque para o setor de corte, que transforma a matéria prima e gera um grande volume de retalhos (MENEGUCCI et al, 2015). Os resíduos têxteis são classificados como resíduos sólidos, de classe II A - não inertes, (LIMA, 2004). Neste contexto, o presente estudo objetivou quantificar os resíduos sólidos provenientes do refilamento da máquina overloque em empresas faccionistas do município de Ibirama-SC.

\section{METODOLOGIA}

Utilizou-se metodologia exploratória, em documentos disponíveis pela prefeitura de Ibirama. Aplicou-se um questionário com perguntas referentes à quantidade de aparas geradas. Para determinação da população amostral, ou seja, o número de empresas participantes da pesquisa, (10\% de erro amostral), foi utilizada a equação 1 (n - tamanho da amostra; N - tamanho da população) (MONTGOMERY e RUNGER, 2005).

$$
n=\frac{(N \times 100)}{(N+100)}
$$

\section{RESULTADOS}

Buscando atender uma maior representatividade dos dados coletados, definiu-se a população amostral pela equação 1 de 67,10. No entanto optou-se em selecionar aleatoriamente 74 empresas. A Figura 1 apresenta as aparas provenientes da máquina de costura overloque, geradas no refilamento.

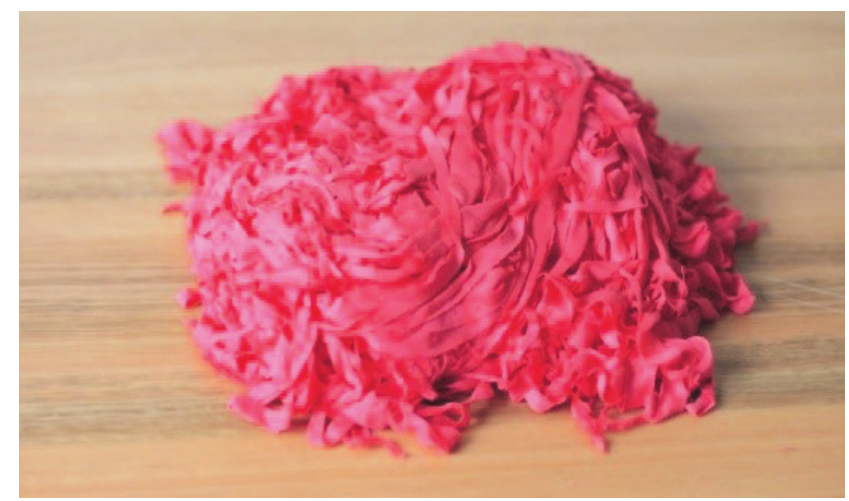

Figura 1 - Aparas do refilamento. Fonte: Autores, 2020.

Em relação à quantidade de aparas geradas nas empresas faccionistas de Ibirama, a produção mensal deste resíduo varia de 150 a $1.300 \mathrm{Kg}$. Na Figura 2 é possível observar a porcentagem de geração de aparas das empresas faccionistas e seus volumes mensais de aparas.
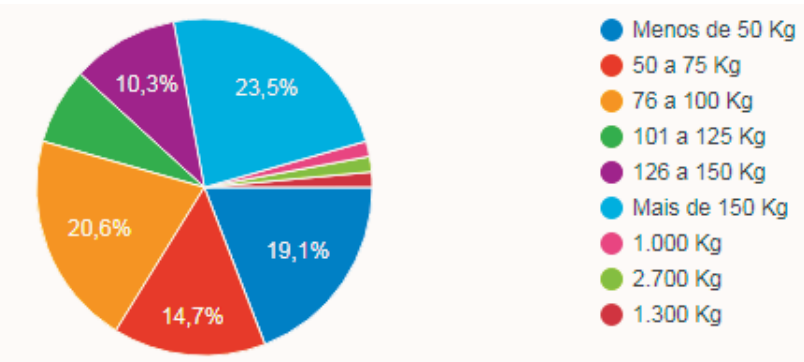

Figura 2 - Volume de aparas geradas nas empresas Fonte: Autores, 2020.

Quanto ao destino das aparas, cerca de 76\% das empresas visitadas contam com serviços de coletas terceirizadas para destinação deste resíduo. Em alguns casos a mesma empresa recicla o material, destina para cooperativas ou ainda direciona para doação. 


\section{CONCLUSÃO}

Pode-se observar que dependendo da empresa faccionista, a quantidade de até $1300 \mathrm{Kg}$. Quanto à destinação correta de aparas, $76 \%$ das empresas visitadas contam com serviços de coletas terceirizadas para destinação deste resíduo, em outros casos, a mesma empresa recicla o material, destina para cooperativas ou até mesmo faz doações.

\section{REFERÊNCIAS}

MENEGUCCI, Franciele; MARTELI, Letícia; CAMARGO, Maristela; VITO, Meriele. Resíduos têxteis: Análise sobre descarte e reaproveitamento nas indústrias de confecção. XI Congresso Nacional de Excelência em Gestão, Rio de Janeiro, p.01-12, ago. 2015.

MONTGOMERY, Douglas C.; RUNGER, George C. Estatística aplicada e probabilidade para engenheiros. [Applied statistics and progability for engineers, 5th ed. [Inglês]. Tradução e revisão técnica de Verônica Calado. 5 ed. Rio de Janeiro: LTC, 2013. xvi, 521 p.

LIMA, L. M. Q. Lixo: Tratamento e biorremediação. 3. ed. São Paulo: Hemus, 2004. 